\title{
A (IN)UTILIZAÇÃO DA EIRELI COMO CONSEQUÊNCIA DA CRIAÇÃO DA SOCIEDADE LIMITADA UNIPESSOAL
}

\section{EIRELI'S LOSS OF UTILITY AS A CONSEQUENCE OF THE CREATION OF LIMITED SOLE PROPRIETORSHIP}

RESUMO: O presente artigo dedica-se ao estudo de uma das inovações provocadas pela Lei $\mathrm{N}^{\mathrm{o}} 13.874$ de 2019, qual seja a criação da sociedade limitada unipessoal. Neste sentido, este trabalho visa a identificar os impactos da possibilidade legal de constituição da sociedade limitada por apenas um sócio na utilização prática da Empresa Individual de Reponsabilidade Limitada (EIRELI), por meio da análise comparativa entre a figura da EIRELI e a figura da sociedade limitada unipessoal (SLU). Nesse contexto, busca-se evidenciar não somente qual é o perfil subjetivo de empresa mais vantajoso para o empresário que quer empreender sozinho, mas também evidenciar as repercussões que a figura da sociedade limitada unipessoal traz para os micro e pequenos empresários e para o fenômeno da "pejotização".

Palavras-chave: Lei da Liberdade Econômica. EIRELI. Sociedade limitada unipessoal.

\begin{abstract}
This article is dedicated to the study of one of the innovations caused by Law Number 13,874 of 2019, which creates the sole proprietorship limited company. In this sense, this work aims to identify the impacts of the legal possibility of setting up a limited liability company by only one partner in the practical use of the Individual Limited Liability Company (EIRELI), through a comparative analysis between the figure of EIRELI and the figure of the limited company sole proprietorship. In this context, we seek to highlight not only the subjective profile of the most advantageous company for the entrepreneur who wants an entrepreneur alone, but also to highlight the repercussions that the figure of the sole proprietorship brings to micro and small entrepreneurs and to the phenomenon "Pejotization".
\end{abstract}

Keywords: Law of Economic Freedom. EIRELI. Limited sole proprietorship.

\section{INTRODUÇÃO}

Em 30 de abril de 2019, o presidente Jair Bolsonaro assinou a Medida Provisória No 881, cunhada de "Declaração de Direitos de Liberdade Econômica", posteriormente convertida na Lei Ordinária No 13.874/19, em 20 de setembro de 2019, a Lei de Liberdade Econômica. Segundo ementa, este ordenamento propõe-se a promover garantias de livre mercado. Nesse sentido, o fundo axiológico que acompanha a Lei de 
Liberdade Econômica é de prestígio ao papel do Estado como agente regulador e normativo da atividade econômica exercida por particulares.

Imbuída desse espírito de proteção à livre iniciativa, a Lei de Liberdade Econômica promove diversas alterações no Código Civil, como no âmbito da desconsideração da personalidade jurídica (arts 49-A e 50, CC), no âmbito da autonomia da vontade (arts 113, 421 e 421-A, CC), das relações interempresariais (Art. 480-A, 480-B), da desconsideração da personalidade jurídica no caso da EIRELI (art. 980-A, § $7^{\circ}$ do $\mathrm{CC}$ ), da sociedade limitada (Art. 1.052, $\S \S 1^{\circ} \mathrm{e} 2^{\circ} \mathrm{CC}$ ), da disciplina do fundo de investimento (arts. 1.368-C, 1.368-D, 1.368-E, 1.368-F).

Diante desse contexto, o presente trabalho interessa-se, especialmente, pela modificação no Código Civil referente à criação da sociedade limitada unipessoal (Art. 1.052, § $1^{\circ}, \mathrm{CC}$ ). Assim, sob este enfoque, este artigo consiste em um esforço para compreender a recente inovação legislativa.

Nesta senda, questiona-se em que medida a Empresa Individual de Responsabilidade Limitada perde sua utilidade prática com o advento desse formato unipessoal da sociedade limitada e quais os impactos que a sociedade limitada unipessoal gera na perspectiva dos micros e pequenos empresários e do fenômeno da “pejotização". Ressalte-se que a Lei de Liberdade Econômica não extinguiu a EIRELI, portanto, perquire-se apenas até que ponto é aconselhável a transformação dos atuais titulares de EIRELI em sociedade limitada unipessoal ou a opção, doravante, pela constituição originária de sociedade limitada unipessoal.

\section{AEIRELI}

Até a lei instituidora da Empresa Individual de Responsabilidade Limitada, a Lei 12.441/2011, o único perfil subjetivo juridicamente possível para apenas uma pessoa natural constituir uma empresa seria o empresário individual. No entanto, esta modalidade subjetiva é uma pessoa física, e, portanto, não goza do princípio da autonomia patrimonial das pessoas jurídicas. Em função disso, enquanto a responsabilidade da sociedade empresária é subsidiária, isto é, os bens pessoais do sócio só podem ser acionados após a execução dos bens sociais, a responsabilidade do empresário individual é direta, ou seja, o empresário individual pessoa natural - responde diretamente com seus bens pelas dívidas contraídas no exercício da empresa. Além disso, a depender da configuração societária, a responsabilidade pode ser limitada, enquanto a responsabilidade do empresário individual será sempre ilimitada. Por essa última razão, o empresário individual deve responder diretamente com todos os seus bens pelos débitos decorrentes do exercício da atividade economicamente organizada

Diante desse cenário, a comunidade jurídica brasileira clamava pela possibilidade de exercer individualmente a empresa sem ter de suportar diretamente e ilimitadamente os riscos da atividade empresarial. Como, até então, só existia a hipótese de ser empreendedor singular na condição de empresário individual, tornou-se uma prática muito comum a constituição de sociedades limitadas proforma, em função das quais um empreendedor se associava a alguém com a finalidade real tão somente de gozar da limitação de de responsabilidade inerente às sociedades limitadas. Dessa forma, verificavam-se sociedades limitadas 
compostas por um sócio que detinha 99\% das quotas e um outro sócio com 1\% restante. Diante desse cenário, a Empresa Individual de Responsabilidade nasce com o objetivo de impedir a criação de sociedades fictícias, ao mesmo passo que oferece aos empreendedores o benefício da limitação da responsabilidade patrimonial.

A princípio, a EIRELI, em razão da falta de precisão do texto original de sua lei instituidora, gerou questionamentos, como: pessoa jurídica pode ser titular de EIRELI? Seria possível uma pessoa jurídica ser titular de mais de uma EIRELI? A doutrina vinha se manifestando por uma resposta positiva aos referidos questionamentos, frente ao silêncio legislativo, levando em conta a máxima do Direito (eminentemente) privado - o que não é expressamente proibido, é permitido. A questão foi solucionada por Instruções Normativas emanadas do Departamento de Registro Empresarial e Integração, órgão que possui funções de orientação, coordenação, supervisão e normatização no âmbito do SINREM (Sistema Nacional de Registro de Empresas Mercantis). A Instrução Normativa No 38 do Departamento de Registro Empresarial e Inovação (IN N ${ }^{\circ} 38 / 2017$ ) assentia para a constituição de EIRELI por pessoa jurídica e a Instrução Normativa $\mathrm{N}^{\circ} 48$ (IN $\mathrm{N}^{\mathrm{0}} 48 / 2018$ ) do DREI afirmava que uma pessoa jurídica pode ser titular de mais de uma EIRELI.

Nessa caminhada, a EIRELI representou avanço para a atividade negocial, na medida em que proporcionou ao empreendedor a possibilidade de exercer a empresa individualmente, sendo-lhe garantido o resguardo do seu patrimônio pessoal frente a eventual fracasso da exploração econômica.

No entanto, a vantagem da limitação de responsabilidade do sócio foi mitigada pela exigência de um capital social mínimo integralizado equivalente a cem mil salários-mínimos. Esse requisito em função do salário-mínimo foi objeto da Ação Direta de Inconstitucionalidade № 4.637, proposta pelo Partido Popular Socialista, arguindo a inconstitucionalidade em razão da violação ao inciso IV do artigo $7^{\circ}$ da Constituição Federal, que veda a utilização do salário mínimo como indexador, ao princípio da livre iniciativa e da isonomia. No entanto, o Ministério Público Federal, em seu parecer, esclareceu que o capital mínimo serve à promoção da segurança jurídica e evita a criação das sociedades limitadas de fachada. Ademais, nota-se que a exigência de um capital social mínimo de tamanha monta inviabiliza o cometimento de fraudes trabalhistas, na forma da contratação de empregados de fato como pessoas jurídicas.

Além dessa característica de exigência de um capital social mínimo integralizado, restava claro que uma pessoa natural poderia apenas ser titular de uma única EIRELI de acordo com o texto normativo original imposto pela Lei $\mathrm{N}^{\mathrm{o}} 12.441 / 2011$. Essas duas características tornavam a EIRELI menos atrativa, ao mesmo tempo em que reforçavam a distinção entre EIRELI e sociedade unipessoal limitada, cuja constituição não era admitida no ordenamento jurídico brasileiro, até a Medida Provisória 881, convertida na Lei 13.874 de 2019.

Neste caminhar, a Lei da Liberdade Econômica incluiu o $§ 7^{\circ}$ do Art. 980-A, que chama atenção pela semelhança com o $\S 4^{\circ}$, originalmente proposto pela Lei 12.441/11, instituidora da EIRELI, mas vetado. O texto normativo do $\S 4^{\circ}$ (vetado) do Art. 980-A afirmava que apenas o patrimônio social da empresa "responderá pelas dívidas da empresa individual de responsabilidade limitada, não se confundindo em qualquer situação com o patrimônio da pessoa natural que a constitui, conforme descrito em sua declaração anual de bens entregue ao órgão competente". A razão do veto foi que a expressão "em qualquer situação" 
poderia gerar divergências quanto à aplicação das hipóteses gerais de desconsideração da personalidade jurídica, previstas no art. 50 do Código Civil.

Já o vigorante $\S 7^{\circ}$ afirma: "Somente o patrimônio social da empresa responderá pelas dívidas da empresa individual de responsabilidade limitada, hipótese em que não se confundirá, em qualquer situação, com o patrimônio do titular que a constitui, ressalvados os casos de fraude”. Nesse caso, ainda não está unificado o entendimento se a EIRELI receberá um tratamento diferente quanto à aplicação do instituto da desconsideração da personalidade jurídica.

\section{SOCIEDADE UNIPESSOAL}

Sociedade origina-se do latim 'societas', que significa uma "associação amistosa com outros". Na lição de Marlon Tomazette (2019, p. 236-237) são elementos gerais de uma sociedade: a existência do consenso, do objeto lícito e da forma prescrita ou não defesa em lei. Assim, entendemos que a constituição da sociedade deve ter como fonte a vontade livre e consciente manifestada por todos os sócios (consenso) e deve atender aos requisitos formais previstos ou não vedados pela lei. Além disso, o objeto social (conjunto de operações que a sociedade se propõe a realizar) deve ser lícito. No que concerne à sociedade empresária, ainda consoante Tomazette, devem estar presentes, também, elementos específicos: contribuição para o capital social, participação nos lucros e nas perdas e a affectio societatis ${ }^{1}$. Alguns autores, como Rubens Requião (1998, p. 357) e Fabio Ulhoa Coelho (1999, p. 381), incluem como elemento específico da sociedade empresária a pluralidade de partes.

Nesse contexto, a ideia de sociedade unipessoal rompe com a noção tradicional da linguagem e da doutrina empresarial a respeito da concepção de sociedade, normalmente referida a uma associação de pessoas. Com a admissão da sociedade unipessoal, desvirtua-se o juízo da sociedade como um agrupamento de pessoas (REINHARD, Yves; CHAZAL, Jean-Pascal. 2001, p. 358). Não obstante, por mais disruptiva que a sociedade unipessoal possa parecer, já é uma tendência em países que visam a limitar a responsabilidade do empresário individual. Coutinho de Abreu (2009, p. 21), Professor da Universidade de Coimbra, admitiu uma reformulação no conceito originalmente defendido para as sociedades, que prescinde de pluralidade de partes, podendo ser uma entidade composta por um ou mais sujeitos.

No que tange ao Direito Brasileiro, antes do advento da sociedade limitada unipessoal, instituída pela Lei $\mathrm{N}^{0} 13.874 / 19$, que pode ser simples ou empresária, já havia hipóteses excepcionais em que a sociedade composta por um único sócio era lícita juridicamente. A primeira refere-se à sociedade subsidiária integral, regulada na Lei de Sociedades Anônimas (Lei $\left.N^{\circ} 6.404 / 76\right)$ no Art. 251 e $\S \S 1^{\circ}$ e $2^{\circ}$.

Art. 251. A companhia pode ser constituída, mediante escritura pública, tendo como

\footnotetext{
1 “O traço mais específico de uma sociedade é a chamada affectio societatis, a vontade de cooperação ativa dos sócios, a vontade de atingir um fim comum" (TOMAZETTE, 2019, p. 241).
} 
único acionista sociedade brasileira.

$\S 1^{\circ}$ A sociedade que subscrever em bens o capital de subsidiária integral deverá aprovar o laudo de avaliação de que trata o artigo $8^{\circ}$, respondendo nos termos do $\S 6^{\circ}$ do artigo $8^{\circ}$ e do artigo 10 e seu parágrafo único.

$\S 2^{\circ}$ A companhia pode ser convertida em subsidiária integral mediante aquisição, por sociedade brasileira, de todas as suas ações, ou nos termos do artigo 252.

Desse modo, a sociedade subsidiária integral é um caso autorizado por lei de sociedade composta por um único sócio, qual seja a sociedade brasileira que detém todas as ações de uma dada sociedade anônima, de forma permanente.

Ainda no âmbito das sociedades anônimas, existe hipótese de existência de sociedade anônima unipessoal de forma temporária, tendo em vista o art. 206 da Lei $N^{\circ} 6.404 / 76$.

Art. 206. Dissolve-se a companhia:

I - de pleno direito:

[...]

d) pela existência de 1 (um) único acionista, verificada em assembleia-geral ordinária, se o mínimo de 2 (dois) não for reconstituído até à do ano seguinte, ressalvado o disposto no artigo 251 ;

$[\ldots]$

Assim, caso a companhia só possua um único acionista, não sendo este acionista sociedade brasileira (Art. 251, Lei 6.404/76), a pluralidade da sociedade anônima deve ser reconstituída até a assembleia-geral ordinária do ano seguinte em relação à assembleia que verificou a unipessoalidade, sob pena de dissolução da sociedade anônima.

Para além, a Lei No 8.906, de 4 de julho de 1994, que dispõe sobre o Estatuto da Advocacia e a Ordem dos Advogados do Brasil (OAB), prevê a possibilidade da constituição de uma sociedade de advocacia composta por apenas um sócio:

Art. 15. Os advogados podem reunir-se em sociedade simples de prestação de serviços de advocacia ou constituir sociedade unipessoal de advocacia, na forma disciplinada nesta Lei e no regulamento geral. (Redação dada pela Lei n ${ }^{\circ} 13.247$, de 2016)

[...]

$\S 7$ o A sociedade unipessoal de advocacia pode resultar da concentração por um advogado das quotas de uma sociedade de advogados, independentemente das razões que motivaram tal concentração. (Incluído pela Lei n ${ }^{\circ} 13.247$, de 2016) $[\ldots]$

Art. 17. Além da sociedade, o sócio e o titular da sociedade individual de advocacia respondem subsidiária e ilimitadamente pelos danos causados aos clientes por ação ou omissão no exercício da advocacia, sem prejuízo da responsabilidade disciplinar em que possam incorrer. (Redação dada pela Lei n ${ }^{\circ} 13.247$, de 2016)

Em função disso, um único sujeito pode, de forma permanente, constituir uma sociedade unipessoal de advocacia, sendo todas as cotas pertencentes a um único titular de CPF. Essa unipessoalidade pode ser pretendida originariamente ou ser formada superveniente em razão da transformação de uma sociedade simples de advogados que perdeu a pluralidade de seus sócios. A sociedade individual de advocacia é necessariamente não empresária, obedecendo às normas de sociedades simples. Entre as vantagens 
comumente relacionadas à sociedade unipessoal de advocacia, constam a liberdade de abrir um escritório sem depender de outro advogado e uma carga tributária reduzida, tendo a sociedade unipessoal de advocacia a possibilidade de aderir ao Simples Nacional.

Como mais uma hipótese de formação lícita juridicamente de sociedade unipessoal, menciona-se a sociedade unipessoal temporária, por prazo não superior a 180 dias. Determina o Código Civil:

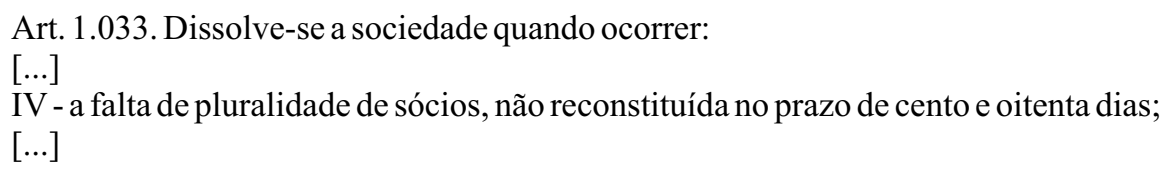

Nessa situação, a sociedade, por alguma razão, perde a pluralidade dos sócios, restando apenas um sócio no quadro societário. Desse modo, para que não haja a dissolução da sociedade, a pluralidade dos sócios deve ser recomposta em até cento e oitenta dias. Essa hipótese excepcional admite a unipessoalidade em consideração aos princípios da preservação e da função social da empresa, uma vez que evitar a extinção da empresa implica proteger interesses referentes a trabalhadores, comunidade, fisco, etc. No que tange ao alcance da aplicabilidade do dispositivo do inciso IV do Art. 1.033, com o surgimento da sociedade limitada unipessoal, essa hipótese de dissolução da sociedade não se aplica mais à sociedade limitada, uma vez que a sociedade limitada mesmo com apenas um sócio, continuará, bastando, para tanto, a alteração do contrato social.

ALei de Liberdade Econômica(Lei 13.874/19), por sua vez, por meio da inclusão dos parágrafos $1^{\circ} \mathrm{e}$ $2^{\circ}$ ao Art. 1.052 do Código Civil, autorizou a constituição originária de sociedade limitada formada por apenas um sócio:

Art. 1.052. Na sociedade limitada, a responsabilidade de cada sócio é restrita ao valor de suas quotas, mas todos respondem solidariamente pela integralização do capital social. $\S 1^{\circ} \mathrm{A}$ sociedade limitada pode ser constituída por 1 (uma) ou mais pessoas. (Incluído pela Lei ${ }^{\circ} 13.874$, de 2019)

$\S 2^{\circ} \mathrm{Se}$ for unipessoal, aplicar-se-ão ao documento de constituição do sócio único, no que couber, as disposições sobre o contrato social. (Incluído pela Lei n ${ }^{\circ} 13.874$, de 2019)

Nessa esteira, o sócio único de uma sociedade limitada frui da limitação da responsabilidade. Nessa medida, realça-se o questionamento acerca da inutilização da Empresa Individual de Responsabilidade diante dessa novidade no ordenamento jurídico.

\section{SOCIEDADE LIMITADA UNIPESSOAL}

A agremiação liberal do país não se conformava com as condições - tidas como entraves - para a constituição de EIRELI, como o requisito da integralização de um capital mínimo correspondente a cem vezes o maior salário-mínimo vigente no país. Sendo assim, a Comissão Mista de Desburocratização, que funcionou no Senado entre dezembro de 2016 e dezembro de 2017, elaborou o Projeto de Lei 10.983/2018, que retira a exigência da integralização de um capital mínimo para a constituição da EIRELI e que permite a 
criação de mais de uma EIRELI por uma pessoa natural. Dessa forma, em outros termos, esse Projeto de Lei visava à transfiguração da EIRELI em sociedade limitada unipessoal, visto que suas modificações retiravam as características que distinguiam a EIRELI da sociedade limitada unipessoal, além do nome. No entanto, esse Projeto de Lei, após a aprovação do Senado em novembro de 2018, não chegou ainda a ser apreciado no plenário da Câmara dos Deputados.

Não obstante, é prudente esperar que, com a Lei No 13.874 de 2019, que institui a Declaração de Direitos de Liberdade Econômica, em vigor desde 20 de setembro de 2019, esse projeto perca a razão de sua propositura e, neste momento, começa-se a perquirir se a própria EIRELI perca sua utilidade prática, se estaria fadada ao desaparecimento. Exibem-se esses questionamentos, pois a referida lei provoca uma modificação no Código Civil em função da qual há a expressa previsão da formação de sociedade limitada por apenas uma pessoa:

Art. 1.052 Na sociedade limitada, a responsabilidade de cada sócio é restrita ao valor de suas quotas, mas todos respondem solidariamente pela integralização do capital social. $\S 1^{\circ}$ A sociedade limitada pode ser constituída por 1 (uma) ou mais pessoas. (Incluído pela Lei no 13.874, de 2019).

Desse modo, cria-se a sociedade limitada unipessoal (SLU), tão desejada pelo empresariado liberal, que viabiliza o exercício da atividade econômica organizada por apenas uma pessoa com o benefício do resguardo patrimonial dos bens pessoais e familiares daquele único sócio. Pontua-se que, quanto ao nome empresarial, a SLU pode adotar firma ou denominação social, tal como há ambas as possibilidades para a sociedade limitada com pluralidade de sócios. Ao tempo em que a Declaração de Direitos de Liberdade Econômica ainda vigia na condição de Medida Provisória No 881 , o Departamento de Registro Empresarial e Integração (DREI) editou, em 11 de junho de 2019, a Instrução Normativa $n^{\circ} 63$. Esse ato normativo alterou regras da Instrução Normativa $n^{\circ} 15$ do DREI, que, conforme a própria ementa, “dispõe sobre a formação do nome empresarial, sua proteção e dá outras providências"², com a função geral de estabelecer regras adequadas às especificidades da SLU no que tange à utilização de firma social pelo sócio de limitada unipessoal. Todavia, nota-se que a referida Instrução Normativa ${ }^{\circ} 63$ não inseriu disposição impeditiva de acatamento de denominação como nome empresarial de sociedade limitada unipessoal, e, à vista disso, é incontroversa a informação de que é facultada à sociedade limitada unipessoal utilizar denominação, até porque a sociedade limitada unipessoal não consiste em um novo tipo de sociedade, apenas em nova hipótese de configuração da sociedade limitada.

Para bem compreender as repercussões desse instituto para o universo negocial, passemos à exposição de diferenças entre a Empresa Individual de Responsabilidade Limitada e a Sociedade Limitada Unipessoal.

Diferentemente da EIRELI, a sociedade limitada unipessoal não exige a integralização de um

\footnotetext{
${ }^{2}$ Disponível em:

http://www.mdic.gov.br/images/REPOSITORIO/SEMPE/DREI/INs_EM_VIGOR/IN_DREI_15_2013_alterada_pela_IN_63_2 019.pdf. Acesso em: outubro de 2020.
} 
capital mínimo nem impede a constituição de várias sociedades limitadas unipessoais por uma mesma pessoa. Em função disso, na ótica dos defensores da desburocratização e da liberdade econômica, a sociedade limitada unipessoal é indubitavelmente mais vantajosa para a atividade empresarial; seria uma versão aperfeiçoada da Empresa Individual de Responsabilidade Limitada do ponto de vista do fomento da atividade empresarial.

Nesta toada, em síntese, EIRELI e sociedade limitada unipessoal conferem ao seu, respectivamente, titular e sócio, responsabilidade limitada. Entretanto, a EIRELI possui restrições que a sociedade limitada unipessoal não demanda: uma pessoa natural só pode ser titular de uma EIRELI, enquanto pode ser sócio constituinte de mais de uma sociedade limitada unipessoal; a constituição de EIRELI só ocorre mediante a integralização de um capital mínimo correspondente a cem vezes o maior salário-mínimo vigente no país (Art. 980-A, Código Civil), enquanto que a sociedade unipessoal limitada não exige capital mínimo integralizado para a sua constituição.

Ademais, em tese, a Empresa Individual de Responsabilidade Limitada restringe-se a atividades empresariais, ao passo que a sociedade limitada unipessoal pode ser empresária ou simples. Por conseguinte, por princípio, atividades de profissionais liberais, não podem ser objeto social de EIRELI, uma vez que não constituem elemento de empresa. No entanto, o exercício da profissão de um profissional liberal pode ser objeto de uma sociedade limitada unipessoal, pois este formato societário pode ser empresário ou simples.

Assim, ante à não exigência de capital mínimo integralizado para a constituição da sociedade limitada unipessoal, diferente da exigência mínima de 100 salários mínimos para a constituição de EIRELI, a atuação do micro e pequeno empreendedor é estimulada. O pequeno empresário, graças à sociedade unipessoal limitada, poderá constituir sua empresa sem sócios, resguardar seu patrimônio particular da execução por dívidas da atividade negocial sem ser obrigado a integralizar, previamente, um capital social mínimo de 100 vezes o maior salário mínimo vigente no País. À vista disso, assinala-se que a sociedade limitada unipessoal é uma opção financeiramente viável para que o pequeno empreendedor não tenha necessidade de investir um valor elevado para começar a atuar no mercado nem suporte integralmente os riscos da atividade economicamente organizada sozinho.

Para mais, não somente a EIRELI pode se enquadrar como microempresa (ME) ou empresa de pequeno porte (EPP), como também a sociedade limitada unipessoal (SLU) é uma modalidade de pessoa jurídica compatível com relação ao enquadramento nesses portes, desde que preencha o critério legalmente previsto da receita bruta anual, nos termos do Art. $3^{\circ}$ e dispositivos seguintes da Lei Complementar $n^{\circ} 123$. Por conseguinte, uma vez a SLU formalmente inserida na definição de microempresa ou empresa de pequeno porte, e estando de acordo com os demais pressupostos fixados pela legislação, a sociedade limitada unipessoal pode aderir ao Simples Nacional, regime tributário alicerçado na Lei Complementar ${ }^{\circ} 123$, de 14 de dezembro de 2006, tendo acesso a um tratamento tributário e previdenciário simplificado e com carga tributária reduzida. Nesse sentido, confirma-se que a sociedade limitada unipessoal é um formato de pessoa jurídica bastante atraente para o pequeno empresário, uma vez que é difícil imaginar que um pequeno 
empresário já tenha reserva de capital equivalente a 100 salários mínimos, tornando inviável a constituição de EIRELI, ou que desperdice a oportunidade de empreender eximindo-se dos riscos da responsabilidade ilimitada e direta que o empresário individual proporcionaria (o empresário individual tem responsabilidade ilimitada e direta, já o sócio da sociedade limitada unipessoal possui responsabilidade limitada e subsidiária pelas dívidas decorrentes de operações sociais).

Vale ressaltar a notável relevância das microempresas e das empresas de pequeno porte para o Estado Brasileiro conforme a própria Constituição Federal. Consiste em princípio da ordem econômica brasileira o "tratamento favorecido para as empresas de pequeno porte constituídas sob as leis brasileiras e que tenham sua sede e administração no País" (Art. 170, IX da Constituição Federal). Além disso, o Art. 179 da Constituição Federal determina:

Art. 179. A União, os Estados, o Distrito Federal e os Municípios dispensarão às microempresas e às empresas de pequeno porte, assim definidas em lei, tratamento jurídico diferenciado, visando a incentivá-las pela simplificação de suas obrigações administrativas, tributárias, previdenciárias e creditícias, ou pela eliminação ou redução destas por meio de lei.

Tendo isso em vista, a sociedade limitada unipessoal, por todas as vantagens apontadas, vai ao encontro dos interesses constitucionais, caracterizando-se como uma proposta que dá relevo à livre iniciativa, elemento fundante da República Federativa do Brasil (art. $1^{\circ}$, inciso IV da Constituição Federal) e da ordem econômica (caput do Art. 170 da Constituição Federal).

\section{CONSIDERAÇÕES FINAIS}

À vista do exposto, a sociedade unipessoal ressignifica o conceito de sociedade, ampliando a visão dessa entidade. Passa-se a admitir algo que pode parecer um equívoco do ponto de vista lógico: a sociedade não mais, necessariamente, pressupõe uma reunião de pessoas. Nesta senda, parece ter razão o novo conceito de societatis proposto por Coutinho de Abreu (2009, p. 21), segundo o qual a pluralidade de partes não é condição sine qua non para a configuração da sociedade, podendo haver um ou mais sujeitos.

Sublinha-se que o instituto da sociedade unipessoal já existia no Direito Pátrio antes da Lei de Liberdade Econômica (Lei No 13.874/19) em casos específicos, como da sociedade subsidiária integral (Art. 251 da Lei de Sociedades Anônimas) e da sociedade unipessoal de advogados e, doravante, passa a vigorar como possibilidade jurídica para a constituição originária de uma sociedade limitada.

Nesse âmbito, conclui-se que a sociedade limitada constituída por apenas um sócio tende a fomentar a atividade negocial do país, visto que dispensa um capital mínimo integralizado para a sua constituição diferentemente da EIRELI, que impõe um capital mínimo integralizado - e beneficia o sócio com a separação patrimonial entre o patrimônio da sociedade limitada e o seu patrimônio particular. Ademais, o sócio da sociedade limitada unipessoal pode optar pelo enquadramento no Simples Nacional, desde que se ajuste aos limites de receita bruta anual, definidos para aquele porte de microempresa ou de empresa de pequeno porte, 
nos moldes do Art. $3^{\circ}$ e dispositivos seguintes da Lei Complementar na Lei Complementar $n^{\circ} 123$. Assim, novos empreendedores serão estimulados a exercer atividade empresarial no Brasil, que, por meio da Lei de Liberdade Econômica, admite esse modelo societário com apenas um sócio, já consagrado pela tradição europeia. Para além, as vantagens da sociedade limitada unipessoal aplicadas ao micro e pequeno empresário coadunam-se com a preocupação constitucional de incentivo às microempresas e empresas de pequeno porte. Startups - empresas de iniciativa disruptiva - ou empresas com pouco tempo de criação também serão favorecidas pela redução dos riscos que a sociedade limitada unipessoal oferece.

No entanto, do ponto de vista das relações trabalhistas a sociedade limitada unipessoal está diante de um desafio que a EIRELI soube contornar justamente pela exigência de um capital mínimo a ser integralizado: a "pejotização". Tendo em vista que, para a constituição da sociedade limitada unipessoal, está ausente o requisito do capital social mínimo integralizado, a abertura é muito mais simples. Nesta senda, é possível que algumas empresas aproveitem essa facilidade para contratar aparentemente uma sociedade limitada unipessoal por meio da celebração de um contrato de prestação de serviços com cláusula de exclusividade, quando, de fato, estão no bojo de uma relação de emprego. Assim, a criação da sociedade limitada unipessoal pode ser encarada como um incentivo à precarização do trabalho consubstanciada na "pejotização" do empregado de fato. Porém, essa possível adversidade não inviabiliza as virtudes da sociedade limitada unipessoal, uma vez que o advento desse formato da sociedade limitada não guarda relação de causalidade com a subversão aos direitos trabalhistas, nem autoriza o cometimento dessa grave infração, que, reunidos os elementos do tipo normativo no plano fático, pode caracterizar crime contra a organização do trabalho conforme o Art. 203 do Código Penal: "Frustrar, mediante fraude ou violência, direito assegurado pela legislação do trabalho. Pena: detenção de um ano a dois anos, e multa, além da pena correspondente à violência".

De todo modo, infere-se que a sociedade limitada unipessoal certamente será o perfil subjetivo escolhido pelos empreendedores em detrimento da EIRELI, haja vista as vantagens já comentadas. Assim, confirma-se que a criação da figura da sociedade limitada unipessoal implicará, muito provavelmente, o desaparecimento prático da EIRELI. No entanto, essa hipótese, por mais que coerente do ponto de vista teórico, deverá ser confirmada empiricamente, depois de decorridos mais anos de vigência da Lei da Liberdade Econômica, e, portanto, da autorização da sociedade limitada unipessoal. Um fator que pode contribuir para a EIRELI não cair em desuso é se a jurisprudência interpretar o $\S 7^{\circ}$ como um dispositivo que confere um tratamento diferenciado em relação à desconsideração da personalidade jurídica, sendo uma contrapartida à exigência de capital mínimo, blindando quase absolutamente o patrimônio do titular. No entanto, a jurisprudência provavelmente consolidará a interpretação do $\S 7^{\circ}$ na parte "ressalvados os casos de fraude" como ressalvados os casos de abuso de direito. Dessa forma, a desconsideração da personalidade jurídica aplicar-se-á à EIRELI como se aplica às demais pessoas jurídicas, consoante a Teoria Maior, tendo em vista a vedação do sistema jurídico pátrio ao enriquecimento ilícito. 


\section{REFERÊNCIAS BIBLIOGRÁFICAS:}

ABREU, Jorge Manuel Coutinho de. Curso de direito comercial. 3. ed. Coimbra: Almedina, 2009, v. 2, p. 21.

ABREU, Maíra Leitoguinhos de Lima. A Tradição Europeia em Sociedade Unipessoal: Comparação com o Brasil. Rev. Fac. Direito UFMG, Belo Horizonte, n. 63, pp. 491 - 527, jul/dez. 2013.

BRASIL. Constituição (1988). Constituição da República Federativa do Brasil de 1988. Brasília, DF: P r e s i d ên c i a d a R e públi c a , [ $\left.\begin{array}{llll}2 & 0 & 1 & 6\end{array}\right]$. D i s p o n ív e 1 e m : http://www.planalto.gov.br/ccivil_03/constituicao/constituicao.htm.

BRASIL. Departamento de Registro Empresarial e Integração - DREI. Instrução Normativa No 38. Institui os Manuais de Registro de Empresário Individual, Sociedade Limitada, Empresa Individual de Responsabilidade Limitada-EIRELI, Cooperativa e Sociedade Anônima. 02 de maio de 2017.

BRASIL. Departamento de Registro Empresarial e Integração-DREI. Instrução Normativa No 47. Altera o Manual de Registro de Empresa Individual de Responsabilidade Limitada - EIRELI, aprovado pela Instrução Normativa DREI n 38 , de 2 de março de 2017.03 de agosto de 2018.

BRASIL. Lei n. 10.406, 10 de janeiro de 2002. Institui o Código Civil. Diário Oficial da União, Brasília, DF, 11 jan. 2002. Disponível em: <http://www.planalto.gov.br/ccivil_03/Leis/2002/L10406compilada.htm>. Acesso em: 30 jan. 2020.

BRASIL. Lei n. 6404, 15 de dezembro de 1976. Dispõe sobre as Sociedades por Ações. Diário Oficial da Un i ão, B rasília, D F, 17 d e z. 1976 . D i s p oníve 1 e m : <http://www.planalto.gov.br/ccivil_03/Leis/L6404consol.htm>Acesso em: 14 jan. 2020.

BURITI, Tamara de Santana Teixeira. A "pejotização" e a fraude ao regime de emprego. Disponível em: http://conteudojuridico.com.br/consulta/Artigos/51273/a-quot-pejotizacao-quot-e-a-fraude-ao-regime-deemprego Acesso em: 30 jan. 2020.

COELHO, Fábio Ulhoa, Curso de direito comercial. São Paulo: Saraiva, 1999, v. 2.

FAQUIM, David Guilherme Antonietti. HARO, Guilherme Prado Bohac de. Criação da Figura da Sociedade

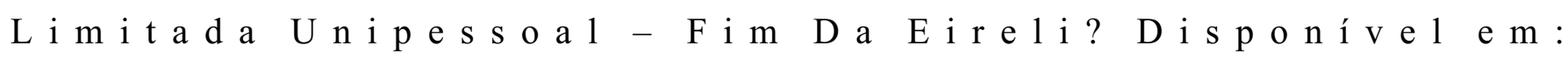
http://intertemas.toledoprudente.edu.br/index.php/ETIC/article/view/8015/67648866 Acesso em: 30 jan. 2020.

FERREIRA, A. B. H. Aurélio século XXI: o dicionário da Língua Portuguesa. 3. ed. rev. e ampl. Rio de Janeiro: Nova Fronteira, 1999.

LEOPOLDINO DA FONSECA, João Bosco. Direito Econômico. 9. ed. rev., atual., e ampl. - Rio de Janeiro: Forense, 2017. 
REQUIÃO, Rubens. Curso de direito comercial. 23. ed. São Paulo: Saraiva, 1998, v. 1.

REINHARD, Yves; CHAZAL, Jean-Pascal. Droit commercial. 6. ed. Paris: Litec, 2001.

RIBEIRO, Marcia Carla Pereira. COSTA, Pedro Henrique Carvalho da. Primeiras Anotações Acerca da Nov a S o c i e d a d e $\mathbf{L}$ i m i t a d a U n i p e s s o a l. D i s p o n íve 1 e m : https://www.cidp.pt/revistas/rjlb/2019/4/2019_04_1123_1145.pdfAcesso em:30 jan. 2020.

TARTUCE, Flavio. Artigo do Professor Pablo Stolze Gagliano sobre a Lei $\mathbf{1 3 . 7 8 4 / 2 0 1 9}$ (Lei da Liberdade Econômica). Disponível em: https://flaviotartuce.jusbrasil.com.br/artigos/760054174/artigodo-professor-pablo-stolze-gagliano-sobre-a-lei-13784-2019-lei-da-liberdade-economica Acesso em: 30 jan. 2020.

TOMAZETTE, Marlon. Curso de direito empresarial : teoria geral e direito societário. Volume 1, 10. Ed. São Paulo : Saraiva Educação, 2019. 